\title{
O Pensamento Social e Político Latino-Americano: etapas de seu desenvolvimento
}

Simone Rodrigues Pinto ${ }^{1}$

Resumo: Este artigo pretende traçar um panorama do pensamento latino-americano, partindo de uma linha histórica mais recente, iniciada pela influência do romantismo e do positivismo nos primeiros anos da independência, a esquerda nascente e os nacionalismos, a emergência do desenvolvimentismo e do dependentismo, finalizando com a perspectiva crítica do pós-colonialismo. A proposta não é descrever as principais correntes e teorias de maneira exaustiva e completa, mas tentar gerar interesse e admiração pelos escritos e escritores latino-americanos de maior destaque, a partir do conhecimento das etapas de seu desenvolvimento.

Palavras-chave: América Latina, Teoria Social, Pensamento Político, Periferia, Subalternidade.

\section{Introdução}

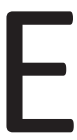
xiste um pensamento latino-americano? Parafraseando a pergunta feita por Salazar Bondy (1968), na década de 1960, esse trabalho busca recuperar e trazer à tona as principais correntes de pensamento - e seus principais representantes - desenvolvidas a partir da América Latina ${ }^{2}$. Ao contrário deste filósofo, que afirmou ser impossível desenvolver um pensamento genuíno e original a partir das Américas, cuja produção intelectual estava condenada a ser inautêntica e imitativa, queremos destacar o desenvolvimento desse pensamento social e político do hemisfério sul, que, nas palavras de Boaventura de Souza Santos é

(...) el reclamo de nuevos procesos de producción y de valoración de conocimientos válidos, científicos y no-científicos, y de nuevas relaciones entre diferentes tipos de conocimiento, a partir de las prácticas de las clases y grupos sociales que han sufrido de manera sistemática las injustas desigualdades y las discriminaciones causadas por El capitalismo y por El colonialismo. (2010, p. 43)

A proposta de Souza Santos é bem mais ousada do que se pretende ser aqui. Ele
1. Doutora em Ciência Política pelo luperj/Ucam. Professora e coordenadora da pós-graduação do Centro de Pesquisa e PósGraduação sobre as Américas (CEPPAC) da Universidade de Brasília. E-mail: smartinsrodrigues @hotmail.com

2. Nesse artigo, não haverá a preocupação, muito pertinente, sobre os usos e abusos do nome "América Latina", "latinoamericano", "Hispano América", etc. por não se tratar da problemática principal proposta aqui. 
3. Malinche é o nome da princesa asteca que se tornou amante e conselheira do conquistador Hernán Cortez. defende formas alternativas de conhecimento e busca dar voz a grupos excluídos, silenciados e marginalizados. Aqui, ao invés de condenarmos o pensamento latino-americano como sendo inautêntico, relegando a produção do continente à mera repetição do que nos é exógeno, pretendemos traçar um panorama do pensamento latino-americano, como grupo excluído dos grandes centros de produção do pensamento mundial. A proposta não é descrever as principais correntes de maneira exaustiva e completa, tampouco aprofundar em conceitos e teorias, mas tentar gerar interesse e admiração pelos escritos e escritores latino-americanos, minimizando a supervalorização do pensamento produzido desde o Norte, fortalecida por um complexo de Malinche ${ }^{3}$ e pela apropriação de uma visão imposta desde a Europa. O grupo silenciado é representado por intelectuais latino-americanos que produziram e continuam produzindo um pensamento político e social compromissado em entender os problemas que afligem a Nuestra América. Portanto, esse artigo centralizar-se-á nas etapas do desenvolvimento da produção intelectual latino-americana no intuito de fornecer um cenário descritivo de suas principais correntes.

A valorização do pensamento latino-americano enfrenta muitos obstáculos, mas quero destacar dois deles: um externo e outro interno. O externo diz respeito à dificuldade de ser reconhecido nos grandes centros. Na visão de Bourdieu (2006), adequada ao que se quer expor aqui, a produção do conhecimento é marcada por uma luta simbólica que reproduz as relações de dominação. Assim, trava-se uma luta concorrencial entre agentes cujas posições se encontram $a$ priori fixadas e, no caso do pensamento latino-americano, o lócus do intelectual é não só inferiorizado, mas também invisibilizado.

O obstáculo interno se traduz em um sentimento de inferioridade, historicamente imposto pelo modelo euroamericano, dentro da perspectiva da modernidade, que nos fez incorporar os dilemas do Calibã e assumir a autoimagem de bárbaros, incapazes de produzir conhecimento de qualidade. A obra teatral de Aimé Cesaire (1997), baseada no original de Shakespeare, ilustra bem o que queremos dizer. Nela, o pequeno espaço do palco serve como recorte do mundo e reproduz as relações centro-periferia, dominantes e dominados, metrópole e colônia. Ali se percebem os matizes da sociedade - o bem e o mal, a riqueza e a pobreza, o negro/índio e o branco, o colonizado e o colonizador - expressos nas figuras de Próspero e Calibã.

Próspero - Decididamente, o mundo está invertido. Teremos visto de tudo: Caliban dialético! Afinal de contas, Caliban, eu o amo... Vamos façamos a paz... nós vivemos dez anos juntos e trabalhamos lado a lado dez anos. Dez anos, isso conta! Acabamos por nos tornar compatriotas! 
Caliban - não é a paz que me interessa, você sabe muito bem! É ser livre. Livre, está me ouvindo! (...) Próspero, você é um grande ilusionista, a mentira, isso você conhece. E de tal modo você mentiu para mim, mentiu sobre o mundo, mentiu sobre mim, que acabou por me impor uma imagem de mim mesmo: um subdesenvolvido, como você diz, um incapaz, eis como você me obrigou a me ver, e essa imagem eu a odeio. E ela é falsa! Mas agora, eu o conheço, velho câncer, e eu me conheço também.

A metáfora do espelho de Próspero, que aparece nos escritos de José Enrique Rodó, de Carlos Fuentes e de Richard Morse, nos ajuda a entender esta dificuldade de olharmos a nós mesmos sem a intermediação do conquistador, do europeu, do outro estrangeiro. Quando analisamos os programas das disciplinas de ciências sociais na academia, percebemos a reiterada tentativa de entender nossos problemas e contingências a partir de modelos exógenos, transplantados sem um compromisso com nossa realidade histórico-social.

Muitos se referem a essa marginalização como maldição, perpetuada desde o processo que culminou com a consolidação das relações de produção capitalistas e o modo de vida liberal, que teve, simultaneamente, uma dimensão colonial e imperial de conquista e submissão de outros continentes. É nesse cenário que as ciências sociais começam a se desenvolver aqui, quando o modelo liberal de organização da propriedade, do trabalho e do tempo deixam de ser uma modalidade civilizatória e adquirem uma hegemonia naturalizada como única forma de vida possível. Epistemologicamente, essa sociedade moderna capitalista favorece a percepção de uma necessária superioridade dos saberes produzidos por ela. O conhecimento chamado científico, produzido nesse contexto hegemônico, adquire um status privilegiado de única ciência viável.

(...) una maldición se cierne sobre América Latina: ha llegado tarde a la historia. Estados sin nación, ciudadanos sin derechos, clases sociales sin proyectos, modernizaciones sin modernidad, industrializaciones sin Revolución Industrial. Maldición que ha impregnado el pensamiento social latinoamericano hasta el extremo de provocar una cierta parálisis cuya característica más burda es el complejo de inferioridad en la producción de conocimientos. (ROSENMANN, 2008, p. 31)

Assim, pretendemos mapear o que tem sido produzido a partir do continente latino-americano, sem a pretensão de esgotar toda a sua contribuição para o conhecimento. Como toda seleção, o risco de deixar de fora nomes e produções significativas é grande. Ainda assim, ousamos tentar chamar a atenção do leitor para o pensamento filosófico, sociológico e político latino-americanos. 
4. Richard Morse (1996) aponta Andrés Molina Enríquez (México), Juan Agustín García (Argentina) e Alberto Torres (Brasil) como patriarcas da sociologia na América Latina, e José Medina Echavarría, Gino Germani e Florestan Fernandes como os responsáveis pela sua consolidação.

5. Bondy estudou no Colégio de México e na Universidad Nacional Autônoma de México, onde conheceu o espanhol José Gaos, o expoente máximo do existencialismo fenomenológico na América Latina e estudioso da história das ideias e desenvolvimento filosófico na Hispano América.
Nossa resposta à pergunta inicial é sim: é possível um pensamento latino-americano; se autêntico e original, depende da perspectiva filosófica que adota o leitor, mas com certeza há uma produção vasta e importante a ser estudada.

Ressaltamos, mais uma vez, que a intenção não será aprofundar em cada uma dessas contribuições. Há limites próprios do formato desse texto. No entanto, desejamos criar, no leitor, o desejo de conhecer mais e de valorizar o que se tem produzido aqui. O legado do pensamento latino-americano é muito rico. Poderíamos discutir os estudos sobre o capitalismo colonial de Sérgio Bagú, os impactos da teoria da relação centro-periferia de Raúl Prebish, o surgimento do sub-imperialismo de Ruy Mauro Marine, os estudos tipológicos de Darcy Ribeiro sobre os povos e o processo civilizatório, a sociologia da fome de Josué de Castro, os conceitos de colonialidade do poder e do saber de Aníbal Quijano, a pedagogia do oprimido de Paulo Freire, as visões da globalização de Octavio Ianni e Celso Furtado, o conceito de fricção interétnica de Roberto Cardoso de Oliveira, a crítica ao neoliberalismo latino-americano de Atílio Borón, a teologia da libertação de Enrique Dussel, as teses sobre culturas híbridas de Néstor García Canclini e muitos outros ${ }^{4}$. Ao invés, no entanto, de trabalhar esses conceitos e teorias, vamos traçar uma linha histórica mais recente, passando pela influência do romantismo e do positivismo, nos primeiros anos da independência, da esquerda nascente e dos nacionalismos, a emergência do desenvolvimentismo e do dependentismo, finalizando com a perspectiva crítica do pós-colonialismo. Mas, antes, podemos perguntar o que seria um pensamento autêntico e original latino-americano.

\section{O Pensamento Latino-Americano é Autêntico e Original?}

O pensamento filosófico latino-americano presente em José Vasconcelos, José Martí, Enrique Rodó, José Carlos Mariátegui e outros, encontra no debate entre o mexicano Leopoldo Zea e o peruano Augusto Salazar Bondy ${ }^{5}$ sua máxima expressão. A grande questão - se existe uma filosofia autêntica latino-americana segue atual. Apesar de ser uma discussão que vem desde o século XIX com Juan Bautista Alberdi, foi com estes dois filósofos que ganhou impulso e repercussão.

Salazar Bondy publicou, em 1968, o livro Existe una filosofía de nuestra América?, questionando a existência de uma filosofia autêntica e original na América Latina. Leopoldo Zea, por sua vez, discute essa problemática em seu livro La filosofía americana como filosofía sin más, publicado em 1969, contestando as teses levantadas por Bondy.

O livro de Bondy (1968) traz três interrogações com relação à filosofia latinoamericana: 
Si há habido o no una filosofía de nuestra América, en caso de respuesta negativa si podría haberla y bajo que condiciones y, por último, hasta qué punto tiene sentido y valor tomar como tema u objeto privilegiado de atención la realidad latinoamericana? (p. 42)

Por meio de uma reflexão sobre os termos originalidade, autenticidade e peculiaridade, o autor conclui que a filosofia produzida pelos pensadores latinoamericanos constitui-se em mera recepção e repetição imitativa do pensamento europeu. Para ele, original refere-se a uma criação inovadora e inédita e autêntica ao que é legítimo, verdadeiro, preciso. Em suas palabras, "el aporte de ideas y planteos nuevos, en mayor o menor grado, com respecto a las realizaciones anteriores, pero suficientemente discernibles como creaciones y no como repeticiones de contenidos doctrinários" (p. 72).

O conceito de autenticidade, por sua vez, é concebido pelo autor como "um producto filosofico - al igual que un produto cultural calquiera - que se da como propriamente tal y no como falseado, equivocado o desvirtuado" (idem). Significa que, quanto ao caráter de autenticidade, a filosofia hispano-americana não o possui, pois se configurou sempre como consciência alienada frente aos problemas mais cruciais de seus países. A partir dessas definições, conclui que os autores latino-americanos não produzem inovações de conteúdo substantivo.

Para Bondy (1968), uma comunidade desintegrada, subdesenvolvida e dependente expressa, pois, uma filosofia sem originalidade e autenticidade. Tal constatação do autor leva à conclusão de que o problema da filosofia hispanoamericana não é um problema da filosofia como tal, mas da comunidade latinoamericana. A alienação decorrente da condição histórica de dominação gera um pensamento igualmente alienado, imperfeito e que não corresponde à realidade. Seria, assim, possível uma filosofia original a partir do momento em que the sejam dadas condições históricas de surgimento, ou seja, tendo sido superada a dependência em que se encontram os países hispano-americanos. A filosofia seria uma crítica radical e destrutiva, aliada a uma práxis política de libertação. A consciência e negação da condição de dominação e subdesenvolvimento poderia ser capaz de desencadear a superação da alienação. Esse deveria ser o papel da filosofia latino-americana. Bondy conclama os pensadores latino-americanos:

(...) orientemos nuestro filosofar, clara y decididamente en el sentido de tratar de cancelar la dominación interior y exterior, o sea, en el sentido de lo que puede llamarse una filosofía de la liberación, que es lo opuesto a la filosofía de la dominación. (1995, p. 94)

Em seu livro Sentido y problema del pensamiento filosófico hispano americano 
(1969), afirma que falar sobre o processo filosófico da Hispano-América é relatar os passos da filosofia ocidental/europeia por sobre os países da região ( $p$. 203). Para ele, é possível listar as características gerais do pensamento hispanoamericano, tais como: pensa-se de acordo com modelos europeus; o que parece uma virtude é algo que mostra nossa falta de conteúdo ideológico (estamos abertos a todas as escolas do pensamento); ausência de uma tendência característica do pensamento; ausência de novas ideias, aportes, teses; sentimento de frustração intelectual, pois os filósofos da região sabem que seus pensamentos não são autênticos; distância entre os filósofos e a comunidade em geral; uma mesma tendência filosófica se apresentou em todos os países hispano-americanos, em função de suas características históricas comuns. Todas essas premissas representam muito bem a rejeição de Bondy da originalidade da produção latino-americana.

Por outro lado, Zea (2002) afirma que há uma tradição de pensamento autenticamente latino-americano e, nesse sentido, a melhor maneira de filosofar, na América Latina, é refletir a fundo sobre nossa peculiar maneira de ser e suas circunstâncias concretas. Para tanto, o caminho mais promissor é o da indagação recuperadora de nossa história e, de modo especial, da história das ideias de nossa América.

O argumento de Zea para combater as afirmações de Bondy baseia-se na ideia de que não precisamos sequer fazer esta pergunta (existe uma filosofia de nossa América?). Ele afirma que, quando nos perguntamos pela existência de uma filosofia americana, estamos assumindo que somos diferentes, "distintos do resto dos homens?", afinal os gregos, ao filosofar, simplesmente pensavam, criavam, ordenavam, separavam, situavam, definiam, ou seja, simplesmente filosofavam (2002, p. 357). Essa postura de se perguntar se podemos fazer filosofia já está presente nas primeiras discussões filosóficas sobre a América Latina. O polêmico debate entre o frei Bartolomé de Las Casas e Juan Guines de Sepúlveda já tinha, por centro, a dúvida sobre a humanidade dos seres nativos, ou seja, dos índios. Portanto, a princípio, a filosofia latino-americana constituiu-se como afirmação antropológica do índio que se sentiu como distinto, diferente do europeu e que, por isso, precisava ser considerado como 'Homem'. Em seguida, século XIX, há na história da filosofia latino-americana o que se denominou "emancipação mental" ou "a consciência do fato da dependência dos países latino-americanos com relação às suas metrópoles" (p. 366) - Portugal e Espanha. A relação de dependência entre colônias e metrópoles, segundo os propugnadores da "emancipação mental", apenas pode ser eliminada com a eliminação da cultura dependente em geral, ou seja, hábitos e costumes herdados das metrópoles, e não apenas eliminando-se a dominação política pela violência. Tal problemática constitui o campo da reflexão filosófica no século XIX, 
juntamente com o Romanticismo, corrente literária e filosófica que põe no contexto cultural latino-americano a questão de uma cultura latino-americana original ou, mais precisamente, de uma cultura nacional tal como as culturas e as identidades nacionais dos países europeus.

Zea cita Antonio Caso, para dizer que se não se pode deixar de imitar, deve-se, pelo menos, inventar um pouco, assimilar. Assimilar significa fazer próprio o que parecia estranho, acomodá-lo ao que se é, sem pretender acomodar o próprio ser ao que the é estranho. Ser original, portanto, é partir de si mesmo, do que se é, da própria realidade e não repetir problemas e questões alheias à sua realidade. Mas ser original não quer dizer, também, ser tão diferente que nada tenha a ver com a filosofia produzida no mundo.

(...) uma filosofia original, não porque acredita uma e outra vez em novos e estranhos sistemas, em novas e exóticas soluções, mas porque trata de dar resposta aos problemas que uma determinada realidade, num determinado tempo, originou. (2002, p. 377)

Zea lança mão da história da filosofia para mostrar que ela deve ser contingencial e jamais universal e transcendente. Repetindo Juan Bautista Alberdi, "não há uma filosofia universal porque não há uma solução universal às questões. Cada país, cada época, cada filósofo teve uma filosofia peculiar (...) porque cada país, cada época e cada escola deram soluções diferentes aos problemas do espírito humano" (ZEA, 2002, p. 379). Essa é a base do argumento de Zea para criticar Bondy. Para ele, o fato de necessitarmos de soluções diferentes e peculiares não significa que não vamos considerar a filosofia europeia como ponto de partida para soluções que, por diferentes que sejam, nem por isso deixam de estar relacionadas com os problemas gerais do homem. $O$ importante é que essa dinâmica não significa que nossa filosofia não seja original.

Zea ainda acusa o europeu que recusa a aceitar a filosofia latino-americana ou a acusa de "imitação" ou "má cópia", o faz porque tem uma orgulhosa pretensão de arquétipo universal (ibidem, p. 384). Nesse sentido, adverte o autor, não se deve buscar a compreensão da filosofia latino-americana pelas semelhanças que tenha com a filosofia europeia: só encontrar-se-ão distorções! É preciso, ao contrário, buscar a relação dessa filosofia europeia importada, com a realidade latino-americana.

Em suma, ele concebe a filosofia latino-americana, ao responder às três interrogações de Salazar Bondy, de forma distinta:

En primer lugar ha habido una tradición de pensamiento auténticamente latinoamericano y dejarla de lado es una de las 
peores y más nefastas actitudes que pueda tomar un pensador que pretenda seguir aportando a ese proceso. En cuanto al segundo aspecto, es indudable que la filosofía es un elemento que debe colaborar en el proceso de destrucción del subdesarrollo y la dependencia presente (...). Con nuestra filosofía sin más o sea, plenamente ideológica en función de la transformación de una realidad intolerable, se garantizará un cambio efectivamente radical. Por último, no sólo cabe pensar en un tema u objeto específico de reflexión, sino que debe advertirse que es el componente ineludible e específico del pensar latinoamericano. (ZEA, 2002, p. 481-482)

Diferentemente de Bondy, Zea afirma que, para ser original e autêntica, a filosofia latino-americana não precisa ser inovadora, ou seja, ela pode beber em outras fontes, mas deve adaptar os cânones da filosofia ocidental à sua realidade. Ele se apoia em uma perspectiva historicista para criticar o universalismo hegemônico e abstrato da filosofia ocidental e afirmar que é necessário filosofar sobre os problemas emergidos das circunstâncias latino-americanas, como expressão histórico-cultural concreta. É justamente nesse esforço que se dará a originalidade e não na "capacidade dos latino-americanos para criar sistemas filosóficos tal como fizeram os filósofos europeus" (idem, p. 480).

A autenticidade estaria, para ele, presente também no processo de assimilação e acomodação do pensamento ocidental à realidade latino-americana, tomando o cuidado de tornar próprios certos valores que se apresentam como universais sem acomodar o próprio ser ao que é estrangeiro. Assim, o que é considerado como "cópias malfeitas do filosofar por excelência vão se convertendo em expressões originais de um pensamento que tem adaptado ou supostamente imitado à realidade que lhe apresenta problemas que urge resolver" (idem).

Leopoldo Zea propõe, pois, uma filosofia plenamente ideológica, capaz de buscar soluções aos problemas da dependência e dominação a que estão submetidos os países latino-americanos; uma filosofia como instrumento de transformação da realidade. Com efeito:

La filosofía es un elemento que debe colaborar en el processo de destrucción del subdesarollo y la dependencia presente (...). Com nuestra filosofía sin más o sea, plenamente ideológica en función de la transformación de una realidad intolerable, se garantizará un cambio efectivamente radical. (ibidem, p. 485) 
Nesse sentido, Zea concebe a filosofia na perspectiva da ação, uma "filosofia da práxis" e ressalta, inclusive, o fato de que tal concepção de filosofia (voltada para a práxis) é tendência crescente no cenário filosófico latino-americano. Tendência que se acentua cada vez mais em contraposição àquelas tendências especulativas presentes na história da filosofia latino-americana dos períodos anteriores.

O debate entre os autores surge em um período de grande efervescência política, social e cultural, em que se lançam os fundamentos da filosofia da libertação na América Latina. Esse debate vai marcar outros pensadores a partir da segunda metade do século XX.

\section{Etapas do Pensamento Social e Político Latino-Americano}

O discurso sociopolítico latino-americano é impregnado por termos como nacionalismo, colonialismo, imperialismo, desenvolvimentismo e outros. Muitos regimes se apropriam desses termos para legitimar suas ações. Em muitos momentos de nossa história, é difícil divisar os agentes políticos dos intelectuais em cujos pensamentos estejam baseados. Muitos associaram suas teorias ao ideal emancipatório e fizeram de sua trajetória uma luta real pela superação das deficiências da região. Alguns intelectuais fizeram uma tentativa genuína de acomodar o pensamento europeu aos problemas regionais, outros não conseguiram perder seu caráter eurocêntrico.

Podemos afirmar que o primeiro grande debate sobre os problemas latinoamericanos foi o realizado por Bartolomé de Las Casas e Juan Guinés de Sepúlveda. Pela primeira vez se discutia a natureza do ser habitante na região e as consequências práticas da filosofia predominante. Na chamada controvérsia de Valladolid (1550-1551), na Espanha, foram produzidos argumentos antropológicos-culturais (a visão do europeu sobre os nativos), teológicos (sobre a evangelização do continente) e filosóficos-jurídicos (sobre a conquista, a escravidão e a guerra). A visão romântica de Las Casas sobre o indígena no continente, homem bom e pacífico, prevaleceu em tese, mas, na prática, a dizimação e a escravidão representaram a realidade. Superado o período da conquista e os debates em torno da relação nativo e conquistador, o positivismo foi a grande influência do pensamento europeu na América Latina.

Ao final do século XIX, a influência do positivismo no pensamento social e filosófico latino-americano era dominante. Segundo Zea,

Después de la escolástica, ninguna otra corriente filosófica ha llegado a tener en Hispanoamérica la importancia que tuvo el 
positivismo. (...) La filosofía positiva trató de ser, en nuestra América independiente, lo que la escolástica había sido en la colonia: un instrumento de orden mental. (ZEA, 1976, p. 2 )

Em diferentes graus, em todos os países, houve baluartes dessa filosofia. Em especial, no México, que foi a base do porfirismo (Porfírio Dias). Na Argentina, a influência também foi destacada, tomando um caráter de liberalismo avançado e socializante, com José Ingenieros e Juan Justo. Em Cuba, cuja linha mestra de todos os pensadores era a independência da ilha, o positivismo esteve mais alinhado com as ideias de Spencer do que de Comte. Sua força se fez presente principalmente na educação.

O liberalismo também deixou sua marca no século XIX. Com a vitória das forças liberais sobre o domínio de Maximilian, no México, em 1867, e a abdicação de D. Pedro II, no Brasil, em 1889, o republicanismo, o constitucionalismo e as instituições representativas passaram a ser o centro das discussões políticas na América Latina. A relação dos liberais com a Europa era ambivalente. Muitos compartilhavam das ideias de Juan Bautista Alberdi, que considerava a civilização latino-americana como parte da europeia e que as ideias desenvolvidas aqui eram apenas uma fase da Revolução Francesa. Para ele, o Novo Mundo representava a possibilidade do progresso humano sob instituições livres, ideal preconizado no Velho Mundo.

No século XIX, também, há uma eloquente expressão de Americanismo, inspirada pelo curto período de beligerância da monarquia espanhola na América do Sul, e se destacam os nomes dos chilenos José Victorino Lastarria, um dos primeiros positivistas, e Francisco Bilbao. Lastarria, em particular, rejeitava a aditivo "latina" associado ao termo América, por ser uma ideia defendida por Napoleão no intuito de restaurar o absolutismo no Novo Mundo (HALE, 1996).

Com o enfraquecimento do positivismo, em alguns setores acadêmicos, principalmente em função dos contornos que tomou enquanto fundamento de regimes políticos, a esquerda passou a ganhar força. A esquerda latino-americana apresentou diferentes conotações ao longo da história - foi nacionalista, anticolonial, revolucionária e até reacionária. A origem do nacionalismo remonta à formação dos Estados Nacionais durante as guerras de independência do início do século XIX. Mesmo que não seja o mesmo processo de constituição da nação no Chile, no México ou no Peru, o nacionalismo foi o eixo central que permitiu a articulação dos diferentes grupos sociais. Nesse momento, os projetos nacionais foram excludentes, principalmente dos índios, mas, mesmo assim, podemos chamar de nacionalismo.

Podemos citar, como grandes articuladores desse nacionalismo, Simon Bolívar 
e José Martí (Cuba). O que Martí defendeu em relação a Cuba, estava também sendo defendido na Argentina ou no Chile. O projeto nacional latino-americano era basicamente da classe média e se baseava na ampliação dos direitos civis, direito a voto, secularização da educação e melhores condições de vida para as maiorias (QUEZADA, 2011).

José Martí é o primeiro ideólogo do que mais tarde, no início do século XX, se chamou de processo de libertação nacional, identificado com as guerras de independência da Argélia, Vietnã e das colônias portuguesas. Ele pregava não somente a independência em relação à Espanha, mas que o rompimento do laço colonial fosse acompanhado de mudança política na estrutura de dominação representada pela presença econômica norte-americana, ou seja, fazer frente ao imperialismo americano. É o primeiro movimento contra o imperialismo dos EUA. Sua obra mais conhecida, Nuestra América (1891), trata de dar sentido à noção de identidade latino-americana e busca valorizar o autóctone, o genuíno. Pode ser considerado o primeiro nacionalista revolucionário porque combina a dimensão nacional (independência política) com a dimensão antimperialista (defesa dos recursos naturais), ideais que serão associados à Revolução Mexicana, vinte anos mais tarde.

Em sua obra, Martí defende que a conquista da América foi possível somente porque havia uma desunião profunda entre os nativos, situação explorada pelos espanhóis para seus propósitos conquistadores. Assim, o tema da unidade americana perpassa toda a sua obra. "Puesto que la desunión fue nuestra muerte, ¿qué vulgar entendimiento ni corazón mezquino ha menester que se le diga que de la unión depende nuestra vida?". (MARTÍ, 1891, p. 353). A questão indígena também é muito presente na obra de Martí. Para ele, a exploração colonial reduziu os nativos à condição de bestas e a tarefa primeira de uma pátria livre seria reverter esta situação. Assim, ele vincula o futuro da revolução americana à raça indígena.

No ano 1900, o romancista uruguaio José Rodó publicou um pequeno ensaio chamado Ariel, que teve grande repercussão entre os intelectuais latino-americanos, principalmente nas duas primeiras décadas seguintes. Evocando um "espírito" latino-americano, Ariel significou um ressurgimento do idealismo por meio de uma revisão do sentido de raça e uma reafirmação dos valores humanísticos e culturais da América Latina. Rodó fazia uma crítica árdua aos valores norteamericanos e à deslatinização do sul do continente. (HALE, 1996). Assim, sua obra se tornou o símbolo do latino-americanismo. A partir dele, surgiu uma geração de "arelistas" nas universidades e nos meios políticos em toda a América Latina, em especial no Peru, com Francisco García Calderón e no México, com José Vasconcelos. 
O inicio do século XX, com a Primeira Guerra Mundial, Revolução Russa e outros eventos históricos de grande repercussão mundial, fez com que a esquerda nascente tomasse fôlego na América Latina. A expansão das economias e a integração da América Latina ao sistema capitalista internacional, facilitando a penetração do capital estrangeiro, provocou um modesto crescimento da indústria e da força de trabalho urbana. Este processo desencadeou uma maciça vinda de imigrantes para algumas regiões e provocou muitas mudanças socioeconômicas que impactaram o mundo das ideias. Um destes impactos foi o desenvolvimento do socialismo na Argentina e no Chile, o surgimento de um indigenismo rural no México e a aparição de uma ideologia, no Peru, que articulava socialismo e indigenismo.

Na Argentina, trabalhadores imigrantes em Buenos Aires constituíam um terreno fértil para a proliferação de movimentos trabalhistas e de diversas correntes socialistas. O Partido Socialista foi fundado por José Ingenieros e Juan Justo, em 1895, mas o movimento anarquista dominou as organizações trabalhistas até o início do século XX. Entre 1880 e 1914, a Argentina era uma sociedade agrária em expansão, com forte incremento do comércio externo, principalmente com a Europa. A Argentina era considerada o celeiro da Inglaterra. Ingenieros elaborou uma proposta com o objetivo de corrigir a miséria e a injustiça social provocada pelo capitalismo, limitando seus efeitos nocivos, sem necessariamente lutar pela sua eliminação. Seus escritos passam a ter grande importância no debate latino-americano sobre o destino da região, em uma época em que a América Latina experimentava grande transformação em suas estruturas econômicas. Em seu livro El suicídio de los bárbaros, Ingenieros (1961) afirma que América, sociedade nova e aberta, liberada do lastre medieval europeu, estaria mais bem preparada para a realização de novos ideais. No entanto, considerava que a realização destes ideais estaria a cargo dos imigrantes e não da população nativa. Chegou a afirmar que "La superioridad de la raza blanca es un hecho aceptado hasta por los que niegan la existencia de la lucha de raza. La selección natural tiende a extinguir las razas de color" (INGENIEROS, 1961, p. 479). Para ele, os imigrantes estariam mais bem capacitados para promover o ideal latinoamericano de crescimento que os indo-americanos. A partir destas ideias, ele discute a noção de "argentinidade" e o papel de uma meritocracia na condução da política.

No Chile, a alma do movimento socialista era o pobre e autodidata tipógrafo Luis Emilio Recabarren. Se em Martí y Ingenieros a revolução era, antes de tudo, uma mudança de valores, da moral, em Recabarren é um processo que depende da ação dos homens, de sua vontade. Em 1912, Recabarren escreveu El socialismo: Qué es y cómo se realizará?, tornando-se a partir daí figura central no desenvolvimento do socialismo no Chile (ZAPATA, 2001). Recabarren 
escreve em uma linguagem clara e acessível os fatores que produzem a riqueza, a mais valia e como o socialismo é o caminho para a justiça social. Insiste em uma luta pacífica e na transformação da sociedade de forma legalizada e institucional. Ele procura conciliar seu papel de intelectual com a de político ligado estreitamente ao sindicalismo salitreiro.

No México, o processo da Revolução Mexicana trouxe à tona a questão da terra e dos indígenas. Consolidada na Constituição de 1917, a filosofia da esquerda mexicana tinha como base a recuperação das riquezas do subsolo, educação para todos e inserção social dos indígenas.

No Peru, não poderia deixar de destacar a influência do radicalismo de González Prada, que inspirou pensadores como José Carlos Mariátegui e Victor Raúl Haya de La Torre. Podemos considerar Manuel Gonzalez Prada ${ }^{6}$ como ponto de partida do questionamento da marginalização indígena e da falta de integração nacional, questionando a ordem colonial como mecanismo que consolidava a oligarquia dominante. Mas lhe faltou a formação de um sistema de pensamento ordenado e um programa de reorganização social. Essa herança coube ao pensamento de Haya de La Torre e de Mariátegui, que impactaram mais profundamente a sociedade peruana (PINTO \& RANINCHESKI, 2009).

Cabe aqui destacar a contribuição do peruano José Carlos Mariátegui que, além de muitas outras questões, desenvolveu um indigenismo que buscava destacar a hipocrisia da ideia de raça. Mariátegui escreveu um conjunto de crônicas, críticas literárias, artigos, ensaios e uma vasta produção literária e teatral. Discutiu temas como nação, educação, trabalho e muitos outros, mas, para ele, o elemento fundamental a ser enfrentado era a "questão indígena". Segundo sua obra, deveria haver uma nova abordagem da questão do índio, que ressaltasse a questão econômica, política e social gerada pela luta pela terra. O centro da questão colonial seria a exploração feudal da população nativa pela grande propriedade agrária. Ainda no Peru, o movimento anti-imperialista surge junto a movimentos de defesa do patrimônio econômico nacional. Ao se opor ao capital estrangeiro, as correntes anti-imperialistas reivindicavam o desenvolvimento da cultura local e a necessidade de uma nação baseada na herança pré-hispânica. $\mathrm{Na}$ verdade, essas ideias representaram a transformação do nacionalismo, que passou a articular desenvolvimento capitalista com afirmação cultural e fortalecimento do Estado. A melhor síntese do movimento anti-imperialista foi a plataforma política da Alianza Popular Revolucionaria Americana (para), de Victor Raul Haya de La Torre.

Haya de La Torre se preocupou em delinear a especificidade da realidade social da América Latina, enfatizando a luta anti-imperialista. Sua visão difere, 
em muitos pontos, da de Mariátegui, em especial quanto ao papel do Estado na organização política. Ele absorve uma interpretação leninista do marxismo e estabelece o Estado como ator central de sua proposta política. Para ele, a alternativa seria a constituição de um Estado anti-imperialista, que assumiria a defesa da nação frente ao capital estrangeiro. Seu projeto envolvia o fortalecimento econômico da América Latina de tal forma que sua inserção no mercado internacional não implicasse em expropriação ou submissão a interesses dos países imperialistas. Quanto à sua aproximação do marxismo, cabe salientar sua consciência de que a teoria marxista não poderia ser meramente transplantada e aplicada mecanicamente a conjunturas latino-americanas (LOWY, 1999). Nos anos 1930, a combinação de nacionalismo, anti-imperialismo e populismo será o projeto predominante da política latino-americana.

Paralelamente, desenvolve-se o socialismo, ligado ao processo de organização sindical, principalmente entre os mineiros. Esse processo foi impulsionado pela chegada de marxistas da Itália e Espanha. A novidade era a explicação da dinâmica social a partir da luta de classes. Os anteriores se fundamentavam na unidade nacional como princípio atuante da política. O diferencial na América Latina era a necessidade de adequar o marxismo ortodoxo à realidade latinoamericana e incluir entre os subordinados a população indígena. Outra noção própria é a de capitalismo dependente. Surgem então as concepções de colonialismo interno, principalmente no México, Peru e Bolívia, que buscava dar conta da dialética entre as relações interétnicas e a luta de classes.

O surgimento do fascismo na Espanha, a crise de 1929 e a Segunda Guerra Mundial ajudaram a criar o cenário que repercutiu nas escolas de pensamento dos anos trinta e quarenta na America Latina. Ainda que os textos mais importantes sobre desenvolvimentismo e modernização começassem a aparecer na década de 1950, devemos tributar méritos à herança dos anos 1930 e 1940. Com a crise de 1929, a relação da América Latina com o resto do mundo modificou-se drasticamente, já que os países latino-americanos não poderiam continuar importando produtos de consumo dos países centrais e o mercado estava cada dia mais fechado para a exportação de matéria-prima produzida aqui. Dessa forma, inicia-se um movimento de substituição das importações por produtos fabricados localmente e as exportações perdem seu caráter estratégico. A mudança na dinâmica econômica leva a modificações na dinâmica política. O enfrentamento de classes cede diante do fortalecimento do mercado interno e a busca de desenvolvimento e modernização passa a ser a palavra de ordem do período que se estende até fins da década de 1950.

O pensamento desenvolvimentista está estreitamente ligado ao trabalho da CEPAL, criada em 1949, como resultado das deliberações do Conselho Econômico e Social das Nações Unidas. Seu primeiro secretário geral, Gustavo Matínez 
Cabañas, foi logo substituído por Raul Prebisch, que tinha uma consistente trajetória na direção de instituições financeiras argentinas. Prebisch e seus colaboradores ${ }^{7}$ editaram em 1950 o primeiro documento de análise da realidade econômica continental, o Estudio Econômico de América Latina. Por muito tempo, o documento foi a base de discussão tanto da evolução como das perspectivas do desenvolvimento da região. Os fundamentos estatísticos apresentados eram, nesta época, inéditos e permitiram mostrar, em termos comparativos, a dinâmica econômica do continente desde o século XIX.

A produção de documentos e relatórios da Cepal era intensa. Neles há uma série de proposições que pretende interpretar o desenvolvimento da América Latina de forma global. O ponto de partida da análise é que a economia mundial é única, onde se distinguem um centro e uma periferia, que se articulam de forma complementar e assimétrica. Uma das propostas para minimizar a desigualdade das relações centro-periferia seria promover o fortalecimento da indústria nacional, a fim de diminuir a dependência das importações. Para buscar esse intento, o Estado se converte na peça central para mediar conflitos e estabelecer medidas de proteção do mercado interno. No campo político, os governos populistas de Getúlio Vargas, Perón e os que se sucederam no México apoiaramse nas doutrinas cepalinas para fortalecer suas posições. Mas, os governos que melhor representaram o desenvolvimentismo na América Latina foram o de Juscelino Kubitschek no Brasil e o de Miguel Alemán no México.

O período de desenvolvimento econômico coincide como rupturas políticas em vários países da América Latina, em que a participação militar nos governos muda consideravelmente a configuração interna dos países. A nova estratégia de desenvolvimento passa a ser acompanhada de endurecimento político, exclusão de vastos grupos sociais do mercado de trabalho, eliminação de leis sociais protetivas do salário e do emprego e promoção de setores ligados à economia de exportação. Por volta dos anos 1960, diante dessa nova conjuntura sociopolítica e econômica, o ser latino-americano é compreendido a partir do binômio dependência-libertação. A primeira expressão teórica dessa interpretação essencialmente política do ser latino-americano aparece no campo das ciências sociais - teoria da dependência. Depois teremos o desenvolvimento do colonialismo interno e da filosofia da libertação.

O novo modelo de interpretação inaugura-se com a publicação dos textos de Andre Gunder Frank, Rodolfo Stavenhagen, Fernando Henrique Cardoso e Enzo Faletto e Ruy Mauro Marini e passa a ser identificado como dependentismo. Os adeptos das teorias dependentistas formularam seu diagnóstico a partir da crítica à teoria da modernização e do desenvolvimentismo que prevaleciam na vida intelectual latino-americana nas décadas de 1950 e 1960.
7. Dentre eles Celso Furtado, Jorge Ahumada e Aníbal Pinto. 
Em comum, os dependentistas têm a crítica aos enfoques centrados na sociedade nacional, como contexto analítico prioritário. Para eles, deve-se compreender o desenvolvimento econômico latino-americano dentro da dinâmica geral de inserção histórica do continente no processo global de expansão capitalista. O centro e a periferia estão ligados a um sistema global cujas características originais foram descritas por Lênin, quando aponta o imperialismo como uma fase superior do capitalismo. Neste mundo, em que o sistema econômico é único, as economias subdesenvolvidas se articulam com o sistema econômico mundial mediante a transferência de recursos da periferia para o centro. Esse intercâmbio desigual gera impedimentos ao desenvolvimento dos países latinoamericanos.

É errôneo crer que os estudos acerca da dependência compartilham uma única perspectiva analítica. Ao contrário, desde que Frank publicou a análise histórica da evolução do Chile e do Brasil, em 1965, até os trabalhos mais recentes, tem havido diversas posições que permitem identificar algumas correntes que, apesar de partirem do mesmo ponto - a relação centro-periferia - divergem nas consequências e nas ênfases dadas ao fenômeno. Existem, pelo menos, três grandes correntes: a de André Gunder Frank, a de Fernando Henrique Cardoso e Enzo Faletto e a de Ruy Mauro Marini.

Gunder Frank liga o marxismo com a análise da dependência e formula uma proposição em que o subdesenvolvimento das formações sociais periféricas tendem a acentuar-se. Por isso, a expressão "desenvolvimento do subdesenvolvimento" (FRANK, 1966). Também busca suprimir a diferenciação entre período colonial e etapa pós-independência, associando dependência e dominação colonial para entender a situação periférica da América Latina. Para Fernando Henrique Cardoso e Enzo Faletto (1996), ao contrário de Frank, o processo de inserção no mercado mundial favorece a expansão do mercado interno e, assim, promove efeitos favoráveis sobre o desenvolvimento da América Latina (neodesenvolvimentismo). Marini (2000) é responsável por um enfoque mais economicista da dependência, ressaltando novos fenômenos ligados à superexploração do trabalho e ao subimperialismo.

Um corolário do debate dependentista é a tentativa de caracterização do processo de desenvolvimento da América Latina a partir da perspectiva do colonialismo interno. O conceito de colonialismo interno surgiu da crítica ao dualismo estrutural, ao desenvolvimentismo e às teorias da modernização. Wright Mills, em seu texto de 1963, intitulado The Problem of Industrial Development, foi, de fato, o primeiro a usar a expressão colonialismo interno, mas González Casanova e Rodolfo Stavenhagen são os principais expoentes da discussão acerca do tema na América Latina. 
Segundo Stavenhagen (1974), a dependência externa é transformada em dominação interna, gerando a polarização da distribuição da renda e da terra. Polarização ecológica, produção concentrada em certas zonas dinâmicas, enquanto outras continuam subdesenvolvidas (backward zones), juntamente com a metropolização da estrutura dentro dos países da região, geram uma espécie de colonialismo interno, que está estreitamente ligado com a estrutura de poder político e, em alguns casos, com a relação interétnica.

Para Gonzalez Casanova (2007), a definição do colonialismo interno está originalmente ligada à conquista da América, em que as populações de nativos não são totalmente exterminadas, mas formam parte, primeiro do Estado colonizador e depois do Estado que adquire uma independência formal. Na época moderna, o colonialismo interno tem antecedentes na opressão e exploração de alguns povos por outros, desde que a articulação de distintos feudos e domínios, característica da formação dos reinos, somou-se no século XVII, à Revolução Inglesa e ao poder das burguesias. Segundo sua análise, os primeiros apontamentos do colonialismo interno encontram-se na própria obra de Lênin "Sobre o direito das nações à autodeterminação" (1914). Circunstâncias anteriores puseram freio intelectual e oficial à reflexão sobre o colonialismo interno. Esse freio deu-se, especialmente, nos países metropolitanos e imperialistas, mas também nas "novas nações". A lógica da construção do Estado e das alianças políticas fez com que a categoria do colonialismo interno fosse objeto sistemático de rechaço. Quando a noção de colonialismo interno foi formulada de maneira mais sistemática na América Latina, sua vinculação à luta de classes e ao poder do Estado apareceu originalmente velada. O conceito começou a ser formulado, sobretudo no marxismo acadêmico, no pensamento crítico e nas pesquisas empíricas, tendo como um de seus pioneiros o próprio Rodolfo Stavenhagen. Dessa forma, os fenômenos de colonialismo interno ligados à luta pela libertação, pela democracia e pelo socialismo ocorrem, efetivamente, somente a partir dos anos 1960, ligados à "nova esquerda". Posteriormente, os movimentos de resistência e por autonomia das etnias e dos 'povos oprimidos' adquirem importância mundial, no final dos anos 1990. A construção de um estado multiétnico, por exemplo, remete à construção de "um mundo feito de muitos mundos", no qual os povos, os trabalhadores e os cidadãos seriam todos protagonistas.

Em A democracia em México, Sociedad Plural, colonialismo interno y desarrollo em AL e Sociologia da Exploração, Casanova expõe suas teses, em que rechaça a visão de que o colonialismo seria relevante apenas em escala internacional. Ali, procura demonstrar como ele se dá também no interior de uma mesma nação, em que determinadas etnias ligam-se a grupos e classes dominantes e dominadas. Os Estados de origem colonial e imperialista, com suas classes dominantes, para Casanova, refazem e conservam as relações coloniais com 
as minorias e as etnias colonizadas no interior de suas fronteiras políticas. 0 mesmo fenômeno dá-se também depois da queda dos impérios, e da independência política dos Estados Nação, cujas variantes dependem da correlação de forças dos antigos habitantes colonizados e colonizadores, ressaltados nas lutas por independência.

O capitalismo "triunfa" sobre projetos comunistas, social-democratas e de libertação nacional. Dessa forma, o autor argumenta, uma política globalizadora (e neoliberal), vinculada às grandes empresas e aos grandes complexos políticomilitares, tenderia a uma integração da colonização inter, intra e transnacional. Por esse motivo, triunfando o capitalismo, agora globalizado e globalizante, o colonialismo interno, exatamente por ter uma relação com o colonialismo internacional, seja de maneira formal ou informal, torna-se uma categoria complexa, que se reestrutura.

O contexto sociopolítico-cultural da América Latina na década de 1960 e o aparecimento da Teoria da Dependência criam um ambiente propício para o surgimento de uma reflexão filosófica libertadora. Essa reflexão é um movimento complexo que agrupa tendências diversas. O marco inicial do surgimento da Teologia da Libertação situa-se na Conferencia de Medellín (1968), como primeiro reconhecimento institucional da Igreja Católica da necessidade de uma teologia latino-americana da libertação. É caracterizada pelo encontro de Deus no pobre, que se configura em toda uma classe de marginalizados e explorados. As transformações operadas pela nova consciência dos cristãos revolucionários em relação ao caráter histórico, econômico e político da dominação latinoamericana, junto com a práxis das lutas por soluções alternativas conduzem à percepção libertadora dos ensinamentos bíblicos, ao caráter político da fé e ao compromisso político com os pobres.

O surgimento da Filosofia da Libertação é posterior ao da Teologia da Libertação. A Filosofia da Libertação, na América Latina, emerge como uma resposta crítica contra a dependência e os paradigmas da modernidade. Nesse sentido, busca romper com as estruturas da totalidade que aliena e domina a partir do centro e oferece uma possibilidade de participação livre e independente. A ética da libertação revela a opressão em diferentes dimensões: nos plano mundial, com países centrais dominando os periféricos; no plano nacional, com a exploração de umas classes sobre as outras; no plano erótico, na relação entre homem e mulher; no plano pedagógico, pela valorização da cultura central em detrimento da periférica e no plano religioso, por fetichismos. De acordo com Dussel (1997), a ética da libertação se fundamenta na crítica ao eurocentrismo e à identidade cultural dominante e na ruptura com a filosofia hegemônica que nega e oprime outras culturas. À luz de uma interpretação marxista da história, esse autor define povo como substância da cultura latino-americana e 
como categoria que designa o conjunto orgânico das classes, etnias e outros grupos oprimidos.

Também surgem outras expressões marcadas pela temática da libertação, como, no campo da educação, a "pedagogia do oprimido" de Paulo Freire. O pressuposto básico da pedagogia do oprimido é a categoria de conscientização. A condição básica da conscientização é que seu agente seja sujeito de sua história e de sua educação. Significa a consciência da realidade e a ação transformadora sobre a realidade, como binômio inseparável. Não basta a reflexão crítica da realidade, mas há a necessidade de organizar-se revolucionariamente para transformar a realidade. A libertação se dá na práxis dos homens dentro da história. Para Paulo Freire, a educação pode desempenhar uma tarefa dominadora, quando representa um ato de pura transferência de conhecimento, ou uma tarefa libertadora, em que é valorizado o caráter ativo e indagador do processo.

$\mathrm{Na}$ esteira da busca de entendimento sobre a situação de subalternidade da América Latina, surgem as teorias pós-coloniais. Embora as teorias pós-coloniais tenham sua origem nas academias inglesas e norte-americanas nos anos 1980, ganhou aportes americanistas principalmente a partir da década de 1990. Os enfoques americanistas ganham novos rótulos - decolonialidade, grupo modernidade/colonialidade, estudos subalternos, etc. -, mas mantêm, como característica central, a tentativa de superar as dicotomias e oposições binárias entre colonizadores e colonizados, entendendo o colonialismo como uma relação de forças onde não cabe qualquer exterioridade. Segundo Quezada (2005), póscolonialismo se resume na máxima "quem tem poder, impõe o discurso".

O livro Orientalismo, de Edward Said, é considerado o primeiro a fazer uma genealogia dos saberes europeus sobre o outro, revelando os vínculos entre ciências humanas e imperialismo. Ele afirma que

(...) os filósofos costumam discutir Locke, Hume e o empirismo sem ter em conta que há uma conexão explícita entre as doutrinas filosóficas destes autores clássicos e a teoria racial, a justificação da escravidão ou argumentos a favor da exploração colonial. (2001, p. 33)

Depois de Said, esse caminho foi seguido por pesquisadores indianos como G. Spivak, Homi Bhabha e Ranajit Guha. As discussões em torno do pós-modernismo, dos estudos culturais e da teoria feminista contribuíram para a institucionalização acadêmica do pós-colonialismo, desenvolvido principalmente por intelectuais provenientes das antigas colônias do império britânico, mas, nesse momento, as discussões estavam ainda fechadas para a problemática típica da Latino-América. 
Alguns autores, como Rolena Adorno e Jorge Klor de Alva, defendem que as teorias pós-coloniais são construções aplicáveis unicamente ao contexto mercantilista das colônias britânicas, nos séculos XVIII e XIX, excluindo, assim, a Hispano América. Peter Hulme (1996) é um dos críticos dessa visão excludente e chama a atenção para o fato de que os precursores do pós-colonialismo, como concebido hoje, são os autores caribenhos Aimé Cesaire, Franz Fanon, Edouard Glissant, Fernanto Ortiz e Roberto Fernández Retamar.

Um dos primeiros a procurar subverter as representações coloniais da América Latina foi John Beverley, fundador do Latin American Subalternal Studies Group, nos Estados Unidos. Mas, o mais conhecido membro desse grupo de estudos subalternos é o argentino Walter Mignolo (1995), com uma vasta produção criticando os paradigmas universalizantes definidos pela modernidade. Ele chama a atenção para o "giro epistemológico" realizado por teóricos como Raúl Prebisch, Darcy Ribeiro, Leopoldo Zea, Rodolfo Kusch, Enrique Dussel e Gustavo Gutiérres, como produtores de conhecimentos não eurocêntricos. Ele retoma o termo cunhado por Retamar e considera como pós-ocidentais aqueles engajados com o desmascaramento das teorias impregnadas de opressão vindas da Europa.

O pós-colonialismo é objeto de muitas críticas. Uma delas diz respeito ao uso capitalista da figura do subalterno. Cabe ressaltar o alerta feito pela chilena Nelly Richard (1996), que aponta a instrumentalização da figura do "subalterno" pelas universidades norte-americanas, a fim de legitimar projetos investigativos e mobilizar recursos financeiros. De qualquer forma, o debate pós-colonial tem suscitado revisões e desconstruções interessantes dos saberes produzidos no continente. Nesse sentido, a principal contribuição encontra-se na necessidade de desnaturalizar a dominação eurocêntrica e situá-la no seu momento histórico, demonstrando como ela foi construída em falsas bases e como as Ciências Sociais serviram de subsídio para sustentar esse paradigma.

\section{Considerações Finais}

O pensamento latino-americano, influenciado pela modernidade ou pela pósmodernidade, não tem nada de homogêneo ou monótono. Seja o romantismo, o positivismo, o nacionalismo, o americanismo, o anti-imperialismo, o socialismo, o desenvolvimentismo, o globalismo ou o anticolonialismo, quando florescem na América Latina, figuram com cores novas e matizes diferenciados. Seria possível um pensamento originalmente latino-americano. Na perspectiva do que foi exposto até aqui, podem não ser tão inéditas as categorias, os conceitos, as interpretações, as metáforas ou as alegorias expressas pelos autores latino-americanos, mas com certeza, representam uma visão viva e original 
da realidade sociocultural e político-econônica do continente. As diferentes contribuições representam narrativas com as quais podemos aprender, apreender, debater e criticar as dinâmicas relacionais nas quais estamos inseridos.

Os saberes produzidos na América Latina transcendem as dimensões do pensamento político, filosófico e social, como privilegiadas neste artigo. Caberia, em outro momento, um estudo mais profundo da arte - poesia, teatro, dança, pintura, escultura, música, etc. - muitas vezes engajada e apaixonada. Nas palavras de lanni (2002),

Nesse vasto e problemático laboratório sócio-cultural e político-econômico que tem sido e continua a ser a América Latina, germinam-se situações e condições, impasses e frustrações, realidades e ilusões, com os quais florecem as ciências sociais e as artes, fertilizando inclusive inquietações filosóficas. ( $p$.

Com a chegada dos europeus, a América ganhou novas identidades. Os séculos de colonização agregaram elementos culturais que provocaram mudanças na visão de si e do outro. Em nossa trajetória, vivemos momentos de valorização da cultura dos habitantes originais, regresso aos modelos europeus, impulsos desenvolvimentistas e projetos de resistência anticolonial. Todas essas ondas contribuíram decisivamente para a formação de nossa autoconsciência enquanto indivíduos e coletividades. Acredito que estamos avançando para uma releitura crítica e madura do pensamento latino-americano. O desenlace é imprevisível e o dinamismo das relações é imprescindível. O importante é continuarmos conhecendo e deixando-se conhecer, assumindo o lugar de onde se fala a fim de produzir um pensamento genuinamente latino-americano, seja lá o que isso signifique.

Abstract: This article aims to trace a panorama of Latin American thought. This panorama begins with the influence of the romanticism and the positivism in the early years of independence, then the rising of the nationalism and the emergence of the so called "developmental-ism" and "dependent-ism". At the end, it presents the critical perspective of post-colonialism. The proposal is not to describe the theories in depth, but to create interest for the most prominent Latin American writers.

Keywords: Latin America, Social Theory, Political Thought, Periphery, Subalternity.

\section{Referências}

BETHEL, L. (Ed.). Ideas and ideologies in twentieth century Latin America. Cambridge University Press, 1996. 
BONDY, S. Sentido y problema del pensamiento filosófico hispanoamericano. Kansas, Center of Latin American Studies, 1969.

. Dominación y liberación. Universidad San Marcos, 1995.

. Existe una filosofia de nuestra America?. Siglo Veintiuno Editores,

1968.

BOURDIEU, P. O poder simbólico. Bertrand Brasil, 2006

CARDOSO, F. H.; FALETTO, E. Dependência e desenvolvimento na América Latina. LTC, 1996

CASANOVA, P. G. "Colonialismo interno (uma redefinição)". In: Boron, Atilio A.; Amadeo, Javier; Gonzalez, Sabrina. A teoria marxista hoje. Problemas e perspectivas. CLACSO, 2007

CASTRO-GÓMEZ, S. "Ciencias sociales, violencia epistémica y el problema de la "invención del otro". In: Edgardo Lander (comp.). La colonialidad del saber: eurocentrismo y ciencias sociales. Perspectivas Latinoamericanas. CLACSO, 2000.

CESAIRE, A. Discurso sobre el colonialismo. Akal, 2006.

Une tempete. Points French, 1997.

DUSSEL, E. Oito Ensaios sobre cultura latino-americana e libertação. Editorial Paulinas, Sao Paulo, 1997, 229 p.

FRANK, A. G. "The development of underdevelopment". Monthly Review, September, 1966.

HALE, C. A. "Political ideas and ideologies in Latin America, 1870-1930". In: Bethell Leslie (ed.), Ideas an ideologies in Twentieth Century Latin America. Cambridge University Press, 1996.

HULME, P. "La teoria poscolonial y la representación de la cultura en las Américas", Casa de las Américas 202, 1996.

IANNI, O. Enigmas do pensamento latinoamericano. São Paulo: IEA/USP, 2002.

INGENIEROS, J. “El suicidio de los bárbaros”. Los Tiempos Nuevos, Losada, 1961.

LOWY, M. Marxismo na América Latina: uma antología de 1909 aos días atuais. Perseu Abramo, 1999. 
MARIÁTEGUI, J. C. Siete ensayos de interpretación de la realidad peruana. Buenos Aires: Ediciones El Andariego, 2005.

MARINI, R. M. Dialética da Dependência. Vozes, 2000.

MARTí, J. "Nuestra América". La Revista Ilustrada de Nueva York, 10 de enero de 1891 .

MIGNOLO, W. “Ocidentalización, imperialismo, globalización: herencias coloniales y teorías poscoloniales". Revista Iberoamericana, 1995

MORSE, R. "the multiverse of Latin American identity", In: Bethell Leslie (ed) Ideas an ideologies in Twentieth Century Latin America. Cambridge University Press, 1996.

QUEZADA, F. El pensamiento contemporáneo. Nicarágua, CIELAC, 2005. ; GÓMEZ, G. El pensamiento latinoamericano. Nicarágua, CIELAC, 2011.

RICHARD, N. "Signos culturales y mediaiones académicas", In: B. Gonzalez Stephan (ed.) Cultura y Tercer Mundo. Cambios en el Saber académico, Caracas, Editora Nueva Sociedad, 1996.

PINTO, S. R.; RANINCHESKI, S. "O pensamento social peruano de José Carlos Mariátegui e Victor Haya de La Torre". In: RANINCHESKI, Sônia Maria; FERNANDES, Ana Maria. (Org.). Américas Compartilhadas. 1 ed. São Paulo: Francis, 2009.

ROSENMANN, M. R. Pensar América Latina. El Desarrollo de la sociología latinoamericana. Buenos Aires, Clacso, 2008.

SAID, E. Orientalismo. Cia das Letras, 2001.

SANTOS, B. Refundación del estado em América Latina. Relaju, 2010.

STAVENHAGEN, R. "The Future of Latin America: Between Underdevelopment and Revolution". Latin American Perspectives, Vol. 1, No. 1, (Spring, 1974), p. 124-148

ZAPATA, F. Ideologia y política en America Latina. Colegio de México, 2001.

ZEA, L. Discurso desde a marginalização e a Barbarie. Garamond, 2002. . El pensamiento latinoamericano. Barcelona: Ariel, 1976. 